\title{
MATEMÁTICA FINANCEIRA: UM ALICERCE PARA O EXERCÍCIO DA CIDADANIA
}

\author{
DUARTE, Paulo César Xavier ${ }^{1}$ \\ VIANA, Diego Sales ${ }^{2}$ \\ TASSOTE, Eliezer Marcos ${ }^{2}$ \\ DIAS, Marcus Vinícius ${ }^{2}$
}

\begin{abstract}
RESUMO: Este artigo disserta sobre os resultados de uma pesquisa que visou à abordagem da matemática financeira ao longo do currículo escolar, discutindo e refletindo sobre a importância do tema e a forma como ele é tratado no ensino médio. Através de uma pesquisa qualitativa, este trabalho tem como objetivo identificar a abordagem que a Matemática Financeira recebe nos livros didáticos, baseando-se nos Parâmetros Curriculares Nacionais e em livros que abordam o tema citado, procurando compreender o modo como ela é trabalhada em sala de aula e como os professores de matemática procuram contextualizá-la com assuntos cotidianos, visando criar perante o aluno a ligação com o seu dia a dia, enfatizando também a necessidade de, através da matemática financeira, trabalhar conceitos de cidadania.
\end{abstract}

Palavras-chave: Matemática financeira; Cidadania; Educação Financeira.

\section{FINANCIAL MATHEMATICS: A FOUNDATION FOR THE EXERCISE OF CITIZENSHIP}

SUMMARY: This article brings the results of a research which has as its aim to analyse the financial mathematics approach throughout the school curriculum. It discusses and reflects about the importance of the issue and how it is treated in high school, emphasizing that this issue is constantly on the student's daily life. Through a qualitative research, this article has as its aim to identify the financial mathematics approach in books based on the National Curricular Parameters and books that analyze the mentioned issue. It is been researched to understand how financial mathematics is worked in the classrooms and how the math teachers contextualize it using everyday topics, aiming to create a connection between the student and his everyday, emphasizing also the necessity, through financial mathematics, to work citizenship concepts.

Keywords: Financial Mathematics; Citizenship; Financial Education.

\section{INTRODUÇÃO}

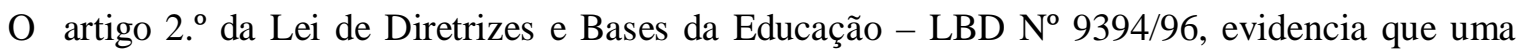
nova educação:

\begin{abstract}
Almeja criar ambientes que possam preparar e educar cidadãos críticos, atuantes e livres, que liberem energia em atividades em grupo; no pensar e no fazer modernos, que sejam questionadores, que participem de uma educação mais humana e fraterna com o emotivo e o artístico presente; enfim, que os futuros cidadãos sejam atuantes e reflexivos em nossa sociedade (p. 15).
\end{abstract}

Nesse contexto, sabendo que as várias áreas do conhecimento contribuem para a constituição dos sujeitos, este artigo enfocará a disciplina matemática e, mais especificamente, a Matemática Financeira, considerando-a um conteúdo amplo para o qual convergem outros conceitos matemáticos, tais como: proporcionalidade, funções lineares e exponenciais, logaritmos, etc., além de se relacionar com novas

\footnotetext{
${ }^{1}$ Doutorando e Mestre em Educação Matemática pela Unesp de Rio Claro- SP e Especialista em Matemática Superior pela PUCMG.

Professor do Departamento de Matemática da UNIVÁS- MG

${ }^{2}$ Aluno da Licenciatura Plena em Matemática da UNIVÁS- MG
} 
tecnologias; planilhas, calculadoras eletrônicas e ferramentas computacionais, podendo ser trabalhada de forma mais próxima ao aluno (DIAS; TASSOTE; VIANA, 2011).

Também, segundo as Diretrizes Curriculares Nacionais para o Ensino Médio (DCNEM):

O tratamento contextualizado do conhecimento é o recurso que a escola tem para retirar o aluno da condição de espectador passivo. A contextualização evoca por isto áreas, âmbitos ou dimensões presentes na vida pessoal, social e cultural, e mobiliza competências cognitivas já adquiridas (BRASIL, 1998, p.79)

Sendo assim, para o aluno, é essencial que durante o aprendizado haja um conhecimento prático que lhe permita resolver problemas do cotidiano, tratar informações de forma crítica o ajudando na tomada de decisões. "Quando esta capacidade é potencializada pela escola, a aprendizagem apresenta melhor resultado" (PCN, 2000, p. 37).

Porém, na contramão do que postulam as técnicas pedagógicas modernas, a matemática tem sido ensinada de forma mecânica, baseando-se na repetição excessiva de exemplos e na reprodução mecânica de exercícios, o que acaba por levar ao fracasso de sua aprendizagem. Segundo os PCN (2000, p. 27):

Esse processo de transformação do saber cientifico em saber escolar não passa apenas por mudanças de natureza epistemológica, mas é influenciado por condições de ordem social e cultural que resultam na elaboração dos saberes intermediários, com aproximações provisórias, necessárias e intelectualmente formadoras. É o que se pode chamar de contextualização do saber.

Esses são aspectos que nos levou a escolher este assunto, isto é aliar a a Matemática Financeira ao exercício da cidadania, e isso será de grande valia na procura em reverter o quadro obscuro relatado em relação ao ensino da Matemática Financeira e lançar idéias na busca por um ensino cada vez mais contextualizado e ligado na formação integral do cidadão (DIAS; TASSOTE; VIANA, 2011).

Isso posto, destacamos nossa questão de pesquisa: Como a Matemática Financeira está sendo abordada em livros didáticos de Matemática da Rede pública municipal de Pouso Alegre- MG?

\section{CONSIDERAÇÕES TEÓRICO-METODOLÓGICAS}

Sabe-se que os desafios impostos aos educadores neste século XXI são de natureza diversa e colocam-se como fortes obstáculos ao alcance do sucesso no processo educacional. Devido à situação que os educadores têm enfrentado, é preciso estar preparado para encarar e vencer os problemas que se apresentam durante o processo, e isso depende muito de oportunidades, conhecimento e, principalmente, muita paciência com os educandos, pois o papel da educação na vida dos estudantes é de suma importância para o futuro deles. Assim, justifica-se a escolha por um olhar mais próximo sobre a Matemática Financeira, que é bastante presente em nosso cotidiano: ao calcular as prestações de um financiamento de um móvel ou imóvel optando pelo pagamento á vista ou parcelado, por exemplo, faz-se necessário o uso de cálculos matemáticos. Devido a essa e outras situações similares e comuns no dia a dia das pessoas, é importante que se tenha uma noção básica do conceito Matemática Financeira (DIAS; TASSOTE; VIANA, 2011).

A LDB (1996), em seu artigo $2^{\circ}$ da lei $\mathrm{N}^{\circ}$ 9.394, também salienta que a educação tem por finalidade "o pleno desenvolvimento do educando, seu preparo para o exercício da cidadania e sua qualificação para o trabalho". Somam-se, também, as orientações dos PCN que apresentam que:

O ensino da matemática deve ser desenvolvido de tal maneira que permita ao aluno compreender a realidade em que está inserido, desenvolver suas capacidades cognitivas e

Nucleus, v.9, n.1, abr.2012 
sua confiança para enfrentar desafios, de modo a ampliar os recursos necessários para o exercício da cidadania, ao longo de seu processo de aprendizagem.

Na educação matemática no Ensino Fundamental, Médio e Técnico, os conhecimentos de Matemática Comercial e Financeira são importante fator de promoção da cidadania e de entendimento do mundo econômico (ROSSETI JÚNIOR; SCHIMIGUEL, 2011, p. 01).

O que se verifica é que a Matemática Financeira deve ser passada aos alunos de modo que estes estabeleçam relações com o cotidiano, pois ela é um importante item na preparação dos jovens para o mercado de trabalho. Sendo assim, os seus conteúdos deveriam constar desde as séries iniciais, como afirma Lima e Sá (2010, p.1):

[...] que os conteúdos dessas disciplinas sejam iniciados desde as primeiras series do Ensino Fundamental. É claro que tais informações devem ser iniciadas adequadamente, explorando o lúdico, simulação de compras e vendas, preenchimento de cheques, historias em quadrinhos, teatralizações, etc.

Rosseti Junior e Schimiguel (2009) também afirmam que:

[...] a introdução ao estudo da Matemática Comercial e Financeira é importante a partir do Ensino Fundamental, no Ensino Médio e no Ensino Técnico, para promover no aluno as habilidades e competências de analisar e avaliar, criticamente, as situações financeiras que se apresentam em sua vida (p.5).

Os conceitos da Matemática Financeira estão interligados com várias situações do dia a dia de cada cidadão, desde uma simples compra em um supermercado, até situações mais complexas, como a obtenção de melhores resultados em aplicações financeiras. Considerando esses aspectos, o que se nota, segundo estudos já realizados, é que nas salas de aula, esse conteúdo simplesmente não é trabalhado ou centra-se na mera aplicação de fórmulas. Segundo Gouveia (2006, p.21),

A Matemática financeira nem sempre é trabalhada nas escolas de Ensino Fundamental e Médio, e quando é oferecida muitas das vezes, fica longe do contexto em que o aluno está inserido. Os conteúdos são oferecidos, na maioria das vezes, de forma a levar o aluno à memorização de fórmulas, que são utilizadas sem saber o porquê sem uma ligação com o seu dia-a-dia.

A Matemática Financeira é transmitida para o aluno de uma forma na qual o conteúdo exposto fica longe do cotidiano em que ele está inserido. Dessa forma, o aluno acaba não entendendo como pode aplicar esse conceito. Isso implica em uma falta de atenção, tanto por parte dos professores, quanto por parte dos alunos. Muitas vezes, o aluno pergunta ao professor onde utilizará ou aplicará tais conceitos, e a resposta é simplesmente que aquela determinada matéria cai no vestibular, o que acaba por gerar uma falta de interesse por parte dos alunos (GOUVEIA, 2006).

Por esse motivo, o preparo do professor torna-se também imprescindível. "Para que o futuro professor esteja preparado para orientar seus alunos no âmbito da matemática financeira, é importante que o mesmo vivencie, durante sua formação, como lidar com tal tema.” (ALMEIDA, 2004, p.13).

Fica, assim, evidente a necessidade de se reformular a forma com a qual trabalhamos a matemática financeira em sala de aula, tendo em vista que um cidadão despreparado financeiramente reflete diretamente na sociedade em que vivemos, trazendo consigo comportamentos prejudiciais a toda sociedade, a qual gira em torno de um mundo capitalista onde o que se visa é o lucro (DIAS; TASSOTE; VIANA, 2011).

O mercado de trabalho busca, atualmente, profissionais capacitados para um bom desenvolvimento de seu negócio. A parte financeira é, sem dúvida, a base de todo o processo e, quando o profissional não 
tem uma visão analítica, o bom desenvolvimento do empreendimento pode ser interrompido, como comentam Rosseti Junior e Schimiguel (2011, p.01):

Conhecer as operações com o dinheiro tem sido um obstáculo enfrentado pelos jovens ao ingressar do mercado de trabalho. Essas dificuldades educacionais criam barreiras para a plena inserção da juventude no mundo do trabalho, diante das exigências de empresas por nome limpo nos cadastros de créditos e devedores.

Além da vida profissional, podemos ressaltar os problemas acarretados na vida particular de cada cidadão, que muitas vezes em sua formação não teve acesso ao aprendizado da Matemática Financeira. A base de tudo é o orçamento financeiro que, ao ser abalado, causa um grande transtorno na vida de todos (DIAS; TASSOTE; VIANA, 2011).

Muniz Junior (2010, p. 02) afirma que: "a população brasileira tem lidado com o dinheiro de maneira desastrosa, onde a falta de informação matemática, inclusive sem foco na tomada de decisões, tem sido um dos principais motivos dessa realidade".

Essas considerações levam a entender que a Matemática Financeira está relacionada com a formação dos cidadãos, sendo útil e de fundamental importância para que as pessoas tenham uma visão analítica e uma vida financeira controlada (DIAS; TASSOTE; VIANA, 2011).

Sem um bom entendimento desses conceitos, torna-se difícil educar financeiramente um cidadão, pois, ao se deparar com uma situação na qual tenha que usar esses conceitos, ele não terá os instrumentos matemáticos para chegar a uma determinada conclusão. "O desconhecimento desse ferramental pode levar a grandes perdas financeiras" (ROSSETI JUNIOR ; SHIMIGUEL, 2009, p. 4). Aprender os conceitos de Matemática Financeira é a base para um bom desenvolvimento da Educação Financeira. A esse respeito, Rosseti Junior e Shimiguel (2009) apresentam o seguinte questionamento:

Como discernir qual a forma mais apropriada de efetuar os pagamentos: em parcelas ou de uma só vez? Responder essa indagação depende de diversos fatores: as taxas de juros e correções cobradas o prazo de pagamentos, a quantidade de prestações, data dos pagamentos assim como a taxa de atratividade, ou seja, a taxa com a qual o dinheiro apresentará melhor rendimento. (p. 5)

E Puccini (2011,p.12), por sua vez, diz que:

A matemática financeira é um corpo de conhecimento que estuda a mudança de valor do dinheiro com o decurso de tempo [...], para iniciar o seu estudo é necessário que se estabeleça uma linguagem própria para designar os diversos elementos que serão estudados e que esses elementos sejam contextualizados com precisão.

Isso posto, vamos observar as abordagens da Matemática Financeira nos livros didáticos e para isto utilizaremos obras indicadas por professores da rede pública de Pouso Alegre- MG. Utilizaremos para isto a pesquisa qualitativa, pois Bicudo (2010, p.106) relata que

[...] o qualitativo engloba a idéia do subjetivo, passível de expor sensações e opiniões. O significado atribuído a essa concepção de pesquisa também engloba noções a respeito de percepções de diferenças e semelhanças de aspectos comparáveis de experiências.

\section{MATEMÁTICA FINANCEIRA: CONCEITOS IMPORTANTES}

Em consonância com as considerações acima, fica claro que, para o pleno domínio da matemática financeira, há alguns conceitos básicos que devem ser assimilados, tais como: Razão, Proporção, Regra de Três (DIAS; TASSOTE; VIANA, 2011).

Vejamos. 
Razão é o quociente de dois números. Observemos o seguinte exemplo: o salário de José é o triplo do de Batista, ou seja, o quociente entre o salário de José e o de Batista é 3, podemos, assim, notar que o quociente de um número por um outro número é útil para podermos compará-los (LAUREANO; LEITE, 1987).Todos esses tipos de comparações são matematicamente explicitados por um quociente chamado razão e proporção é a igualdade de duas razões (SPINELLI; SOUZA, 1998).

O conceito Regra de Três é uma importante ferramenta para a resolução de problemas que envolvam vários valores dos quais não conhecemos a totalidade. Através da Regra de Três, pode-se estabelecer um valor desconhecido (GONÇALVES, 2011).

O conceito Juros pode ser entendido como o custo do uso do dinheiro alheio, ou seja, é como se fosse um aluguel que pagamos para usar um dinheiro que não é nosso (DANTE, 2000).

Aplicando uma certa quantia (capital) em uma caderneta de poupança por um certo intervalo (tempo), essa tal aplicação funciona de modo como se o aplicador estivesse fazendo um empréstimo do banco. Sendo assim, no final do intervalo de tempo, o aplicador recebe uma determina quantia (juros) como compensação, essa compensação é chamada de juros (DANTE, 2000).

Nos sistemas de juros, existem os juros simples e os juros compostos, ou seja, quando uma determinada soma de dinheiro está aplicada a juros simples, os juros ocorrentes são calculados sobre o montante inicial e, quando uma soma está aplicada a juros compostos, os juros são calculados não apenas sobre o capital, mas também sobre os acréscimos dos juros já vencidos (GONÇALVES, 2011).

A compreensão desse conceito é uma forte ferramenta para formar um cidadão financeiramente educado, pois a todo o momento se depara com situações onde o conceito de juros se faz necessário para tomar decisões.

Para Laureano e Leite (1987), capital

[...] é uma riqueza capaz de produzir renda sem a intervenção do trabalho. Associamos a este conceito a ideia de juro, que é a remuneração da locação de um capital ou, em outras palavras, o custo do uso do crédito. Assim, o juro corresponde simultaneamente ao preço do tempo de utilização de um capital e ao preço do risco que corre o credor.

Capital ou principal é a quantia inicialmente disponível para uma transação econômica (DANTE, 2000). Já Montante, refere-se ao capital acrescido dos juros de um certo período de tempo de uso (DANTE, 2000).

O termo porcentagem vem do latim per centum, que significa por cento. Deparamo-nos com tal conceito em situações de nosso cotidiano, como jornais revistas e noticiários (GIOVANNI; BONJORNO; GIOVANNI JUNIOR, 1994).

Laureano e Leite (1987) definem Taxa como um valor combinado em um empréstimo, ou seja, refere ao custo do dinheiro.

No âmbito da aplicação prática, pode-se dizer que, nos casos em que se aplica a matemática financeira, há sempre uma relação com o cotidiano, na qual a falta desses conhecimentos pode acarretar perdas (DIAS; TASSOTE; VIANA, 2011).

Os conceitos de Matemática Financeira são extremamente importantes para a formação de um cidadão financeiramente educado. Muniz Junior (2010, p.04), comenta que:

[...] a educação financeira está inexoravelmente relacionada à construção dessas competências, principalmente ao processo de construção da cidadania, pois na medida que aumenta a capacidade de análise em situações financeiras, como decidir entre comprar à vista ou a prazo, identificar descontos em sistemas de financiamento, estimar o crescimento do capital investido, dentre outros, o consumidor, tem condições mais efetivas de exercer seus direitos por saber a matemática envolvida nessas situações. 
O conhecimento da Matemática Financeira permite o bom uso dos conceitos da Administração Financeira, pois, através desse conhecimento, o indivíduo terá segurança em tomar decisões em relação aos investimentos. Esses conceitos devem ser usados por todos os indivíduos em quaisquer situações em que uma decisão financeira se fizer necessários (GONÇALVES, 2011).

Além dos conceitos matemáticos, existem vários elementos que compõem a boa Educação financeira, dentre eles, as planilhas eletrônicas também são fundamentais para a organização do orçamento e reflexões da vida financeira, como comenta Muniz Junior (2010):

[...] recursos tecnológicos amplamente disponíveis, como planilhas eletrônicas e calculadoras científicas; refletir e analisar matematicamente o aumento da expectativa de vida do brasileiro e seus impactos na economia nacional, incluindo sua própria aposentadoria, seguros em geral e previdência complementar [...] Essas questões certamente devem fazer parte da educação financeira dos alunos que comporão a população economicamente ativa de um país(p.02).

Existem vários recursos que possibilitam a boa estruturação financeira, e auxilio no orçamento financeiro tanto familiar como no mercado de trabalho.

O Excel é uma forte ferramenta para o controle de atividades financeiras, pois ele disponibiliza diversas funções e tem a capacidade de programações que automatizam cálculos trabalhosos. Sendo assim, a utilização desse software pode auxiliar na educação financeira dos alunos, levando em consideração que esse programa está disponível em quase todos os computadores (FEIJÓ, 2007).

As calculadoras financeiras são muito utilizadas nos cálculos financeiros, pois, além de auxiliarnos, elas os tornam mais rápidos, como comenta Vannucci (2003):

Os cálculos matemáticos aplicados à área financeira ganharam muito em agilidade, com $\mathrm{o}$ advento das calculadoras financeiras, cujas funções, desenvolvidas especialmente para essa área, deixaram para trás as tão conhecidas tabelas financeiras (p.15).

Com o surgimento das calculadoras financeiras, houve uma evolução e um importante auxílio no ensino, pois as calculadoras financeiras tornaram o processo mais dinâmico, já que as elas possuem funções para resolver problemas específicos de matemática financeira (FEIJÓ, 2007).

Com os conhecimentos necessários a Matemática Financeira caminhará para uma relação mais lúdica, prazerosa, edificante por parte dos alunos e, sem dúvida, será uma matéria capaz de despertar total interesse tanto nos educandos como também nos educadores (ROSSETI JUNIOR; SCHIMIGUEL, 2011).

\section{MATEMÁTICA FINANCEIRA E CIDADANIA}

A educação financeira é algo discutido com frequência em vários setores de nosso cotidiano, porém muitas pessoas não possuem certa compreensão do significado dos temas relacionados com essa educação, pois consideram erroneamente que a educação financeira está apenas relacionada a aprender a investir em ações .

Isso nos remete a Theodoro (2011) que nos diz que:

[...] a Educação Financeira é o processo pelo qual os indivíduos e a sociedade melhoram a sua compreensão em relação aos conceitos sobre os produtos financeiros de maneira que com informação, formação e orientação clara possam desenvolver os valores e as competências necessárias para se tornarem mais conscientes das oportunidades e riscos neles envolvidos, e então poderem fazer escolhas bem informadas (p. 26).

Savoia, Saito e Santana (2007) reforçam, dizendo que: 
A educação financeira tornou-se uma preocupação crescente em diversos países, gerando um aprofundamento nos estudos sobre o tema. Embora haja criticas quanto à abrangência dos programas e seus resultados, principalmente entre a população adulta, é inegável a importância do desenvolvimento de ações planejadas de habilitação da população (p. 3)

Segundo estudos já realizados pelo professor e pesquisador André Saito, o processo de educação financeira está sendo desenvolvido de forma mais intensa em alguns países, sendo eles: Estados Unidos, Austrália, Japão, Coreia do Sul e Nova Zelândia. Já nos países da América Latina e Leste Europeu, o processo de educação financeira está ocorrendo de forma bastante lenta (SAITO apud MUNIZ JUNIOR 2010 p.1).

Embora o Brasil esteja se desenvolvendo mais lentamente em relação à educação financeira que outros países, já existem grupos que se preocupam com tal tema. "Desde 2007, o ${ }^{3}$ COREMEC formou um grupo de trabalho que pesquisa e debate procedimentos para ampliar o nível de compreensão do brasileiro em relação à administração do dinheiro (MACHADO 2011, p.3).

Machado (2011) cita um decreto de lei publicado no Brasil envolvendo a educação financeira, nos seguintes termos:

Em 23 de Dezembro de 2010, o presidente Luis Inácio "Lula" da Silva promulga o decreto m. 7.397, instituindo a Estratégia Nacional de Educação Financeira - ENEF, para promover a Educação Financeira, envolvendo BACEN, Ministério da Fazenda, Educação, Justiça, Previdência Social o CONEF, que representa 4 entidades da iniciativa privada (p. 3).

Os esforços federais também já se estenderam aos estados; em março de 2011, foi inaugurada a primeira escola de educação financeira no Rio de Janeiro, sendo esta a primeira desse ramo no país. Essa escola irá oferecer palestras e cursos sobre finanças pessoais, mercado financeiro, entre outros temas envolvendo assuntos de educação financeira (MACHADO, 2011).

A educação financeira, além de suas características matemáticas, possui uma importante relação com o exercício da cidadania e com a formação do cidadão, possibilitando ao aluno conhecimentos que lhe trarão uma qualidade de vida melhor, uma consciência econômica e social e, principalmente, o preparo para o exercício da cidadania (DIAS; TASSOTE; VIANA, 2011).

Assim sendo, o ensino de Matemática não pode deixar de lado estas considerações. Os PCN relativos ao ensino médio dizem que:

Em um mundo onde as necessidades sociais, culturais e profissionais ganham novos contornos, todas as áreas requerem alguma competência em matemática e a possibilidade de compreender conceitos e procedimentos matemáticos necessários tanto para tirar conclusões e fazer argumentações, quanto para o cidadão agir como consumidor prudente ou tomar decisões em sua vida pessoal e profissional, (PCN, 1999, p.40)

Assim, não devem ser ignorados exemplos evidentes, como o agravamento da recente crise financeira mundial, a qual refletiu diretamente em grande parte da sociedade. Essa crise, provocada sobretudo pela especulação financeira imobiliária e pela falta de controle das instituições bancárias americanas, causou transtornos orçamentários e sociais em todos países. As notícias publicadas pelos

${ }^{3}$ Comitê de Regulação e Fiscalização dos Mercados Financeiro 
veículos da mídia exaustivamente trazem oscilações nos índices: das bolsas de valores, da taxa de câmbio, das taxas de juros, da inflação, e outros indicadores financeiros e sociais. Quando o ensino da matemática não visa preparar o aluno para analisar essa e outras situações do cotidiano, ele acaba o excluindo do seu direito de exercer a sua cidadania de uma forma contundente (DIAS; TASSOTE; VIANA, 2011).

Também é importante ressaltar que uma das necessidades da educação é atender às prioridades sociais. O ensino da matemática também deve caminhar neste sentido. Duarte (2010) atenta para o fato de que o mercado de trabalho exige profissionais mais preparados e pessoas dispostas a sair da acomodação, que questionem e busquem alternativas (DIAS; TASSOTE; VIANA, 2011).

Assim, salientando uma contradição na falta de ligação entre o ensino matemático e a vida real, percebe-se que as mesmas crianças que devolvem o troco corretamente no comércio, fabricam suas próprias pipas utilizando conceitos de geometria e marcam o campo de futebol corretamente, fracassam na matemática formal da sala de aula (DIAS; TASSOTE; VIANA, 2011).

Dessa forma, é preciso refletir se a prática pedagógica atual contribui para a inclusão social, para a prática da cidadania e se a escola está contribuindo para o processo educacional (DUARTE, 2010).

A educação financeira pode dar sua contribuição à formação do cidadão e também para o exercício da cidadania, pois ela contribui na formação da autonomia advinda da confiança na própria capacidade, para enfrentar os desafios e confiança na tomada de decisões.

Segundo Frankeberg (2006):

O que mais almejamos na vida é felicidade, saúde, e tranquilidade financeira. Felicidade é apenas um estado de espírito, que depende unicamente de nós mesmos. Saúde, infelizmente, em algumas vezes independe da nossa vontade. Tranquilidade financeira não depende da sorte, mas quase que exclusivamente de um bom planejamento financeiro. Entramos aqui em um fator realmente importante. Eu não sou de filosofar . Sou um homem pratico. Acho que o nosso país necessita, alem da educação formal, da educação financeira, porque muita coisa da nossa vida depende dela.(p. 25 ).

"A carência de educação financeira expõe os agente a riscos, o que acarreta danos não apenas às suas vidas, mas também à sociedade como um todo" (MACHADO, 2011 p.10)

A educação financeira contribui para um cidadão ter controle de seus próprios gastos e, assim, possuir uma vida financeiramente controlada.

Segundo Theodoro (2011):

A falta de planejamento financeiro, seja para um estado, empresa ou individuo, leva à vulnerabilidade, insegurança e a falta de autonomia que, no nível familiar, pode ocasionar instabilidade conjugal, degradação dos valores éticos, e ainda doenças psicossomáticas como o estresse, por exemplo, comprometendo a qualidade de vida significativamente.

Isso posto, a educação financeira pode auxiliar as crianças a compreenderem o valor do dinheiro e a entender, desde cedo, à importância de poupar. Já aos estudantes e aos jovens, ela pode trazer importantes competências para viver de forma independente. Para os adultos, ela auxilia no planejamento de grandes conquistas em sua vida, tais como realizar o sonho da casa própria, os gastos diários de sua família, o planejamento para os estudos dos filhos e, principalmente, a preparação para a aposentadoria (MACHADO 2011).

\section{MATEMÁTICA FINANCEIRA PRESENTE EM ALGUNS LIVROS DIDÁTICOS DO ENSINO MÉDIO}

Devido à importância dos livros didáticos, justifica-se a realização de uma pesquisa qualitativa 
através de uma observação sobre os mesmos, a qual pode vir a contribuir para a melhoria no ensino e na abordagem da matemática financeira no sistema escolar.

Segundo Gatti Júnior (2004),

Sua origem está na cultura escolar, mesmo antes da invenção da imprensa no final do século XV. Na época em que os livros eram raros, os próprios estudantes universitários europeus produziam seus cadernos de textos. Com a imprensa, os livros tornaram-se os primeiros produtos feitos em série e, ao longo do tempo a concepção do livro como "fiel depositário das verdades científicas universais" foi se solidificando (p.36).

Isso posto, são observados alguns livros didáticos utilizados pelas escolas públicas de Pouso Alegre- MG, indicados pelos professores que os utilizam, procurando abordar, durante essa observação, os capítulos sobre matemática financeira.

Os livros indicados foram:

- Matemática Fundamental - volume único dos autores José Ruy Giovanni, José Roberto Bonjorno e José Ruy Giovanni Junior, publicado pela Editora FTD em 1994;

- Matemática - volume dois do autor Manoel Paiva, publicado pela Editora Moderna em 1995;

- Matemática para o ensino médio - volume único, dos autores Carlos Alberto Marcondes dos Santos, Nelson Gentil e Sergio Emílio Grego, publicado pela Editora Àtica em 1998;

- Matemática - volume único dos autores Gelson Iezzi, Osvaldo Dolce, David Degenszajn e Roberto Périgo, publicado pela Editora Saraiva em 2005;

- Matemática Ensino Médio - volume três, das autoras Kátia Stocco Smole e Maria Ignez Diniz, publicado pela Editora Saraiva em 2010.

Procurou-se variar, durante o processo de indicação das obras para observações, os anos em que os livros foram publicados - como se pode observar, 1994 a 2010. Devido a esses critérios, será possível observar o desenvolvimento nos capítulos que tratam de assuntos referentes à matemática financeira (DIAS; TASSOTE; VIANA, 2011).

Matemática Fundamental - Volume único dos autores: José Ruy Giovanni; José Roberto Bonjorno e José Giovanni Jr.

Nesse livro, foi encontrado apenas um único capítulo que envolve algum assunto referente à matemática financeira. Esse capítulo trata de Porcentagem.

$\mathrm{Na}$ apresentação do capítulo, o autor já relata uma situação problema envolvendo preços e mercadorias, a qual é interessante, pois ele trata de um problema contextualizado, vejamos:

$\left.1^{\circ}{ }^{\circ}\right) \mathrm{O}$ preço de uma mercadoria sofreu um aumento de $\mathrm{R} \$ 250,00$. Na sua opinião, esse aumento é pequeno ou grande?

2..$\left.^{\circ}\right)$ Na compra de uma mercadoria, obtive um desconto de $\mathrm{R} \$ 250,00$. Na sua opinião, esse aumento é pequeno ou grande?

Para responder a essas perguntas, precisamos saber qual era o preço da mercadoria antes do aumento ou antes do desconto.

Nas duas situações, se a mercadoria em questão custasse $\mathrm{R} \$ 5000,00$, é claro que o aumento ou o desconto de $\mathrm{R} \$ 250,00$ seria considerado pequeno.

Porém, se a mercadoria custasse $\mathrm{R} \$ 500,00$, tanto o aumento como o desconto seriam considerados muito grandes. 
Assim, um aumento ou um desconto de $\mathrm{R} \$ 250,00$, pode ser considerado pequeno ou grande, dependendo do valor com o qual o estamos comparando.

\section{Matemática - volume dois do autor Manoel Paiva}

Esse livro trata do assunto de matemática financeira como extensão do capítulo de progressões geométricas.

O capitulo é especificado como: "progressões geométricas em cálculos de juros compostos", talvez seja esse um dos motivos por que o autor exclui o conteúdo de juros simples. Como justificativa por tal exclusão, o autor cita que os juros compostos são frequentemente usados nas transações financeiras.

$\mathrm{Na}$ introdução do capítulo, o autor define de forma exemplificada os conceitos de capital, juro, montante e taxa. Para demonstrar a fórmula de juros compostos, ele utiliza uma tabela, que pode ser montada pelos alunos com o auxílio do Excel. Nos cálculos exponenciais, o autor fornece o resultado ao invés de sugerir aos alunos que busquem o resultado por meio de calculadora financeira ou científica, o mesmo caso também ocorre quando aparecem o cálculo de logaritmo nos exercícios propostos.

Para demonstrar a fórmula para o cálculo do montante com juros compostos e taxa variável, o autor utiliza conceitos de progressões geométricas.

\section{Matemática para o Ensino Médio - Volume único dos autores: Marcondes, Gentil e Sérgio.}

Os autores dedicam apenas três páginas do livro para o capítulo de matemática Financeira e se prendem a três principais tópicos: porcentagem, juros simples e juros compostos. Deixando de lado na abordagem desses tópicos outros conceitos fundamentais que estão correlacionados à matemática financeira e perdendo a oportunidade de contextualizar com assuntos já estudados no ensino médio como: função exponencial, logaritmos e regra de três simples e composta. Logo no início do capítulo, falta uma pequena introdução mostrando ao aluno do que a matemática financeira e o motivando a prosseguir na leitura do capítulo.

Ao começar na exposição do conteúdo, o primeiro tópico e porcentagem que eles pretendem abordar por meio de exemplos diretos, ele exemplifica a matéria em cinco situações evidenciando sempre a parte fracionaria e buscando relacionar o conteúdo com exemplos comerciais:

A) Dar um desconto de $25 \%$ significa reduzir $25 / 100$ do valor original;

B) Um televisor custa $\mathrm{R} \$ 420,00$ e esta sendo vendido com desconto de $15 \%$. Vamos calcular seu novo preço.

\section{Matemática Volume Único: Gelson Iezzi, Osvaldo Dolce, David Degenszajn Périgo., Roberto.}

Logo no início do capítulo, nota-se a falta de uma introdução, de modo que o conteúdo é exposto de forma direta, sem nenhum comentário prévio sobre o assunto. O primeiro tópico refere-se aos conteúdos de razão e proporção, seguido de porcentagem. Após estas primeiras abordagens, vem às definições de juros e, mais especificamente, juros simples e juros compostos.

Ao abordar o primeiro assunto, nota-se que há uma atenção dos autores em revisar os conceitos de razão e proporção, os quais são importantes para a aprendizagem dos conteúdos subsequentes. Eles procuram definir os conceitos de razão e proporção por meio de exemplos contextualizados, trazendo o assunto para o cotidiano do aluno: Na fila de guichê de vendas de ingressos havia 48 torcedores, sendo 20 palmeirenses e 28 corintianos; a razão entre palmeirenses e corintianos é de 20/28.

Após esta definição, seguem exercícios propostos.

Ao abordar o segundo tópico, eles expõem o conceito de porcentagem de forma sucinta, dizendo 
apenas que se trata de uma razão cujo denominador é igual a 100, e continuam explicitando cerca de 7 exemplos resolvidos sobre o tema. Logo seguem os exercícios que são bastante variados, envolvendo conceitos anteriores e análise de dados e gráficos.

\section{Matemática Ensino Médio - Volume 3 dos autores: Katia Stocco Smole e Maria Ignez de Diniz.}

Os autores dedicam o primeiro capítulo de seu livro para tratar de assuntos referentes à Matemática Financeira.

Para iniciar o capítulo, encontramos uma pequena introdução com uma situação problema envolvendo o tema do capítulo. Nessa situação problema, as autoras apresentam uma situação em que a carência dos conceitos pode causar transtornos, observemos tal situação, que se encontra na pagina 10.

Em seguida, são definidos os conceitos de Matemática Financeira, os quais são tratados como "A linguagem da Matemática Financeira”.

Os conceitos de juro simples e compostos são tratados por meios de exemplos contextualizados, onde os alunos entram em contato com situações dos dia-a-dia que envolve os conceitos. Um fato importante é que, a todo o momento, nos exercícios, as autoras mostram como efetuar as contas tanto na calculadora científica e até mesmo com alguns recursos da calculadora comum.

\section{CONCLUSÕES DAS OBSERVAÇÕES DOS LIVROS DIDÁTICOS}

Os livros didáticos devem ser adotados como um importante meio de auxiliar o professor, pois são materiais que buscam ensinar a Matemática de modo que a aprendizagem seja significativa para o aluno (DANTE 2002).

Passaremos a indicar algumas observações referentes às obras trabalhadas.

\section{Matemática Fundamental - Volume único dos autores: José Ruy Giovanni; José Roberto Bonjorno e José Giovanni Jr.}

Vimos que os autores propõem vários exercícios, sendo a maioria envolvendo valores de mercadorias, aumento, desconto, investimentos, lucros entre outros conceitos envolvendo a matemática financeira. Sendo assim, entende-se que o autor estudou a fundo o conceito de porcentagem, porém, notase que faltaram vários outros conceitos básicos de matemática financeira que é essencial para os alunos (DIAS; TASSOTE; VIANA, 2011).

\section{Matemática - volume dois do autor Manoel Paiva}

Nesta obra, entendemos que o autor poderia ter revisado alguns conceitos do ensino fundamental, os quais são de suma importância para a aprendizagem da matemática financeira uma vez que os alunos geralmente não lembram de tais conceitos (DIAS; TASSOTE; VIANA, 2011).

\section{Matemática para o Ensino Médio - Volume único dos autores: Marcondes, Gentil e Sérgio.}

Após exemplos de porcentagem, os autores passam a falar sobre juros simples e define esse conceito como um valor a ser acrescentado a um capital ao término de determinado período, e logo parte para os exemplos, seguido pela definição de juros compostos, também dados através de exemplos. Por fim, para fechar, ele propõe exercícios de fixação.Sendo assim, notamos a falta exercícios contextualizados para que os alunos possam entender que a matemática é uma matéria muito utilizada no cotidiano (DIAS, M.V; TASSOTE,E. M. ; VIANA, D.S, 2011). 
Matemática Volume Único: Gelson Iezzi, Osvaldo Dolce, David Degenszajn Périgo., Roberto.

Ao tratarem de juros, os autores já iniciam com uma situação-problema contextualizada, evitando até mesmo um formalismo desnecessário para os alunos. Deixando evidente que juros se tratam de uma quantia paga por usar um dinheiro durante um determinado tempo. Logo em seguida, já expõem o conceito de juros simples, apresentando exemplos diretos ao inserirem a fórmula de juros simples e do cálculo do montante, deixam de demonstrar passo-a-passo o surgimento das fórmulas, e concluem a exposição da matéria com juros compostos, também por meio de exemplos. Os autores fecham o capítulo com uma lista de exercícios e testes de vestibular. Sendo assim, notamos que os autores expõem o conteúdo de forma simples e acessível aos alunos, sendo necessário ressaltar apenas a falta de alguns conceitos que são importantes para a aprendizagem.(DIAS, M.V; TASSOTE,E.M.; VIANA, D.S, 2011).

\section{Matemática Ensino Médio - Volume 3 dos autores: Katia Stocco Smole e Maria Ignez de Diniz.}

A didática empregada pelas autoras é simples, dinâmica e acessível à linguagem do aluno. O livro apresenta o conteúdo de forma clara, e os exercícios contextualizados colaboram para que a aprendizagem seja eficaz.Os aspectos teóricos também foram colocados de forma clara, de modo que os alunos se interessam em saber as origens da matemática.

Percebemos que as autoras foram felizes ao desenvolver o capítulo de matemática financeira, pois mostram a realidade dos conteúdos trazendo-os realmente para o cotidiano, o que colabora com a aprendizagem eficaz, sentimos apenas a falta da revisão de alguns conceitos importantes (DIAS; TASSOTE; VIANA, 2011).

Isso posto, podemos observar que cada autor expõe o assunto de matemática financeira de uma maneira diferente, mas o importante é que cada um deles persegue o objetivo de levar ao leitor uma visão geral sobre o assunto. Foi possível notar que, em todos os livros analisados, com especial destaque para o último deles, os autores procuraram expor os conceitos de matemática financeira de forma muito clara, contextualizando todos os exercícios e trazendo situações do cotidiano para facilitar a aprendizagem. Sendo assim, notamos que, em todas as obras analisadas, os autores procuraram cada um a sua maneira, facilitar o processo de ensino aprendizagem e assim, formarem cidadãos para o exercício da cidadania

\section{CONSIDERAÇÕES FINAIS}

A princípio, pode-se verificar que a Matemática Financeira é uma ferramenta importante para o exercício da cidadania, pois, sem ela, o cidadão pode sofrer grandes transtornos. Essa constatação só se confirma ao analisarem-se as condições atuais da sociedade e o modo como há pessoas desinformadas e desprovidas dos mecanismos necessários para conduzir seus próprios estudos econômicos, mantendo-se dentro do planejamento.

Acredita-se, aqui, que este artigo procurou demonstrar uma visão da Matemática Financeira e de com esta foi abordada em livros didáticos indicados, utilizando uma pesquisa qualitativa, ressaltando sua importância na inserção na vida dos cidadãos para estes exercerem a cidadania.

Isso posto, a Matemática pode ser vista e compreendida em seu funcionamento, criando assim uma ponte que pode servir de início aos interessados em desenvolver uma prática de ensino consciente e significativa, bem como para aqueles que tenham interesse na área e queriam conhecer um pouco mais. 


\section{REFERÊNCIAS}

ALMEIDA, A. C.. Trabalhando matemática financeira em uma sala de aula do ensino médio da escola publica. 2004. Dissertação (Mestrado em Educação), Campinas.

BICUDO, M.A V. Pesquisa qualitativa em educação matemática.Belo Horizonte: Autêntica, 2010

BRASIL, Ministério da Educação e do Desporto. Lei de Diretrizes e Bases da Educação Nacional. Brasília: MEC/SEF, 1996

BRASIL, Ministério da Educação e Desporto. DCNEM. Brasília: MEC/SEF, 1998

BRASIL, Ministério da Educação e Cultura. Parâmetros curriculares nacionais. Brasília: MEC/SEF, 2000.

CHOPPIN, A.. História dos livros e das edições didáticas: sobre o estado da arte. [on-line] Revista Educação e Pesquisa, São Paulo, v.30, n.3, p. 549-566, set./dez. 2004. Tradução de Maria Adriana C. Cappello. Disponível em:

<http://www.scielo.br/pdf/ep/v30n3/a12v30n3.pdf>. Acesso em: 20 fev. 2008.

DANTE, L. R.. Didática da resolução de problemas de matemática. São Paulo: Ática, 12º ed., 2002.

DANTE, L. R.. Matemática: Contexto \& Aplicações. V. 1. São Paulo : Ática, 2000.

DIAS,M.V, TASSOTE, E.M, VIANA, A matemática financeira: um alicerce para o exercício da cidadania. 2011. Trabalho de Conclusão de Curso (Licenciatura em Matemática).: Universidade do Vale do Sapucaí. Pouso Alegre.

DUARTE, P. C. X.. Desenvolvendo cidadãos atuantes por meio do ensino aprendizagem de matemática. Porto de Ideias, São Paulo, 2010.

FEIJÓ, A. B.. O ensino de matemática financeira na graduação com a utilização da Planilha e da calculadora: uma investigação comparativa. Disertação (Mestrado em Educação em Ciências e Matemática), Porto Alegre, 2007.

FRANKENERG, L.. Planejamento financeiro: o caminho para transformar sonhos em realizações. São Paulo, 2006. Disponível em:

http://www.akatu.org.br/Content/Akatu/Arquivos/file/OConsumoConscienteDinheiroeCredito.pdf .

Acesso em: 14 set 2011.

GATTI JÚNIOR, D.. A escrita escolar da história: livro didático e ensino no Brasil. Bauru: Edusc; Uberlândia: Edufu, 2004.

GIOVANNI, J. R.; BONJORNO, J. R.. Matemática Fundamental 2 Grau. São Paulo: FTD, 1994

GODOY, A. S. Introdução a pesquisa qualitativa e suas possibilidades, In: Revista de Administração de Empresas, V.35, n.2, Mar./Abr. 1995, p 57-63. MAANEN, John, Van. Reclaiming qualitative methods for organizational research: a preface, In Administrative Science Quaterly, vol.24, no.4, December 1979, p. $520-526$.

GONÇALVES, A. R.. Matemática para o ensino de pedagogia. Disponível em: www.reisdofaroeste.com.br/documentos.Data de acesso: 13 de set 2011.

GOUVEIA, S. A. S.. Novos caminhos para o ensino e aprendizagem de matemática financeira: construção e aplicação de webquest. 2006. Dissertação (Mestrado em Educação Matemática), Rio Claro. 
LAUREANO, J. L.; LEITE, O. V.. Os segredos da matemática financeira. São Paulo: Ática, 1987.

LIMA, C. B.. SA, L. P.. Matemática financeira no ensino fundamental, Revista TECCEN - Vol 3, n. 1, abril de 2010. Disponível em:

http://www.uss.br/web/revista_informativo5/artigo03.pdf Acesso em: 21 nov.2010.

MACHADO, L. H. M.. Educação financeira, perspectivas, antecedentes e visão global. Disponivel em: http://www.ihmachado.com/avisos/artigo . Acesso em: 12 set 2011.

MUNIZ JUNIOR, I.. Educação financeira: Conceitos e contextos para o ensino médio. X Encontro Nacional de Educação Matemática, Salvador, 2010.

NASCIMENTO, P. L.. A Formação do aluno e a visão do professor do ensino médio em relação à matemática financeira. 2004. Dissertação (Mestrado em Educação Financeira), São Paulo.

NEVES, J. L.. Pesquisa qualitativa - características, usos e possibilidades. Caderno de pesquisas e, administração, São Paulo, V.1, No 3, $2^{\circ}$ Sem./1996. Disponível em: http://www.ead.fea.usp.br/cadpesq/arquivos/c03-art06.pdf. Acesso em: 03 nov. 2011.

OLIVEIRA, R. S. ․ Educação financeira em sala de aula na perspectiva da etnomatematica. 2007. Dissertação (graduação em Pedagogia), Bauru.

PAIVA, M. R.. Matematica 2. São Paulo: Moderna, 1995.

PEREIRA, S. C. B.. Sequência Didatica: Fabula. Disponivel em: <http:// www.diaadiaeducacao.pr.gov.br/portals/pde/arquivos/327-2.pdf> Acesso em: 11 set.2011.

PUCCINI, E. C.. Matemática Financeira.Disponível em:

http://www.proativams.com.br/files_aberto/Livro\%20de\%20MForiginal.pdf Data de acesso: 13 set 2011.

ROSETTI JUNIOR, H.; SHIMIGUEL, J.. Educação Matemática Financeira: conhecimentos financeiros para a cidadania e inclusão. Revista Cientifica Internacional, ano 2, n. 8, out 2009.

ROSETTI JUNIOR, H.; SCHIMIGUEL, J.. A História do dinheiro e a Educação Matemática

Financeira. Disponível em: <http://www.administradores.com.br> Acesso em: 19 de março de 2011.

ROSETTI JUNIOR, H. R.; SCHIMIGUEL, J.. Endividamento de jovens, educação financeira e cidadania. Disponível em: http://www.administradores.com.br Acesso: 19 mar. 2011.

SANTALÓ, L.. Didática da matemática: reflexões psicopedagógicas. 35. ed., São Paulo: Cortez, 1997.

SANTOS, C. A. M.; GENTIL, N.; GRECO, S. E.. Matemática para o ensino médio. São Paulo: Ática, 1998.

SAVOIA, J. R. F.; SAITO, A. T. ; SANTANA, F. de A.. Paradigmas da educação financeira no Brasil. Rev. Adm. Pública [online]. 2007, vol.41, n.6, pp. 1121-1141. ISSN 0034-7612. http://dx.doi.org/10.1590/S0034-76122007000600006. Data de acesso: 10 de ago 2011

SMOLE, K. S.; DINIZ, M. I.. Matemática: ensino médio. Volume 3. São Paulo: Saraiva, 2010.

SPINELLI, W.; SOUZA, M. H. S.. Matemática comercial e financeira. São Paulo: Ática, 1998.

THEODORO, F. R. F.. A educação econômico-financeira na formação profissional: uma analise diagnostico: produtiva. Dissertação (Mestrado em Tecnologia), São Paulo, 2011

VANNUCCI, L. R.. Cálculos financeiros aplicados e avaliação econômica de investimento.

São Paulo: Texto Novo, 2003. 